\title{
SIMULATION OF NATURAL CONVECTION IN A SQUARE CAVITY WITH PARTIALLY HEATED AND COOLED VERTICAL WALLS
}

\author{
E. Evren Selamet ${ }^{1}$, A. Selamet ${ }^{2}$, and R. Dehner ${ }^{3}$ \\ ${ }^{1,3}$ Ohio State University, Center for Automotive Research, USA \\ ${ }^{2}$ Ohio State University, Mechanical and Aerospace Engineering, USA
}

\begin{abstract}
Natural convection driven by temperature differences between partially heated and cooled vertical walls in a square cavity is studied numerically. Steady or unsteady cellular flow structures and temperature patterns are illustrated along with the evolution of heat transfer rates in terms of Nusselt number. The cavity is filled with fluids of various Prandtl number, including .024 (liquid metal), .71 (air), 6 (water), and 450 (silicon oil). The effect of Prandtl and Rayleigh numbers on the flow regime and heat transfer is established along with two different thermal boundary conditions.
\end{abstract}

KEY WORDS: Natural convection, Prandtl number, Rayleigh number, instability

\section{INTRODUCTION}

The natural convection heat transfer has been the subject of the many studies since this phenomenon occurs in a wide variety of practical applications such as electronic equipment cooling, heat exchangers, solar collectors, and crystal growth. Following the classical work of Ostrach (1952), extensive experimental and numerical investigations have been conducted on both the heating and cooling aspects as applied to a combination of different geometries, boundary conditions, and fluids, leading to invaluable insight on buoyancy-driven flow regimes and heat transfer. Many focused on the well-known heat transfer physics in an enclosure with one wall maintained hot and the other (opposing wall) cold, while the remaining surfaces were kept adiabatic. Recently, natural convection in cavities with nonuniform wall temperature distribution received considerable attention due to its advantages in some engineering applications. Among these, relatively early work of Kubleck et al. (1980) and Poulikakos (1985) have studied natural convection in an air-filled rectangular enclosure with a single vertical wall accommodating both hot and cold regions (involving a step change in temperature in between) and the remaining three walls being adiabatic; Bilgen and Yedler (2007) considered a similar air-filled rectangular enclosure with one of side walls subjected to a sinusoidal temperature profile, while retaining the other three as adiabatic walls; also investigating an airfilled rectangular cavity, Deng and Chang (2008) imposed sinusoidal temperature distribution on side walls combined with adiabatic top and bottom walls. Sivasankaran and Pan (2014) investigated the effect of amplitude and phase deviation of sinusoidal temperature distribution of side walls in a cavity with adiabatic horizontal walls. More recently, Adnani et al. (2016) considered an air- and water-filled cavity with lower half of the side walls maintained hot and the upper half cold, while keeping top and bottom walls adiabatic.

The step change in wall temperature considered in some of the foregoing studies has motivated the present work. Recently, Evren-Selamet and her co-workers studied natural convection in square and elbow-shaped enclosures filled with air/liquid metal (2015), and finned cavities filled with air (2017) and liquid metal (2018). The objective of the current work is to expand on these steady/transient computational solutions in order to bring further insight into natural convection in a square cavity filled with variety of fluids where 
each of the two side walls is now subject to two different temperatures. One crude model for that type arrangement may be a closed area heated by some sort of heat sources on side walls and cooled off by windows. Following this brief Introduction, governing equations and boundary conditions are described next along with a brief referral to the numerical procedure. The results are discussed in Section 3, leading then to conclusions in the final section.

\section{DEFINITION and FORMULATION}

Present study considers a square cavity with two different boundary conditions as illustrated in Fig. 1: (a) lower halves of the side walls are maintained hot (at temperature $T_{H}$ ) and the upper halves cold $\left(T_{C}\right)$; (b) left wall remains identical to Fig. 1a, while swapping hot and cold regions of the right wall, that is, now the upper half of right wall is hot and the lower half cold. Hereafter, these cases are referred to as $\mathrm{BC} 1$ and $\mathrm{BC} 2$, respectively. The top and bottom walls are both adiabatic.

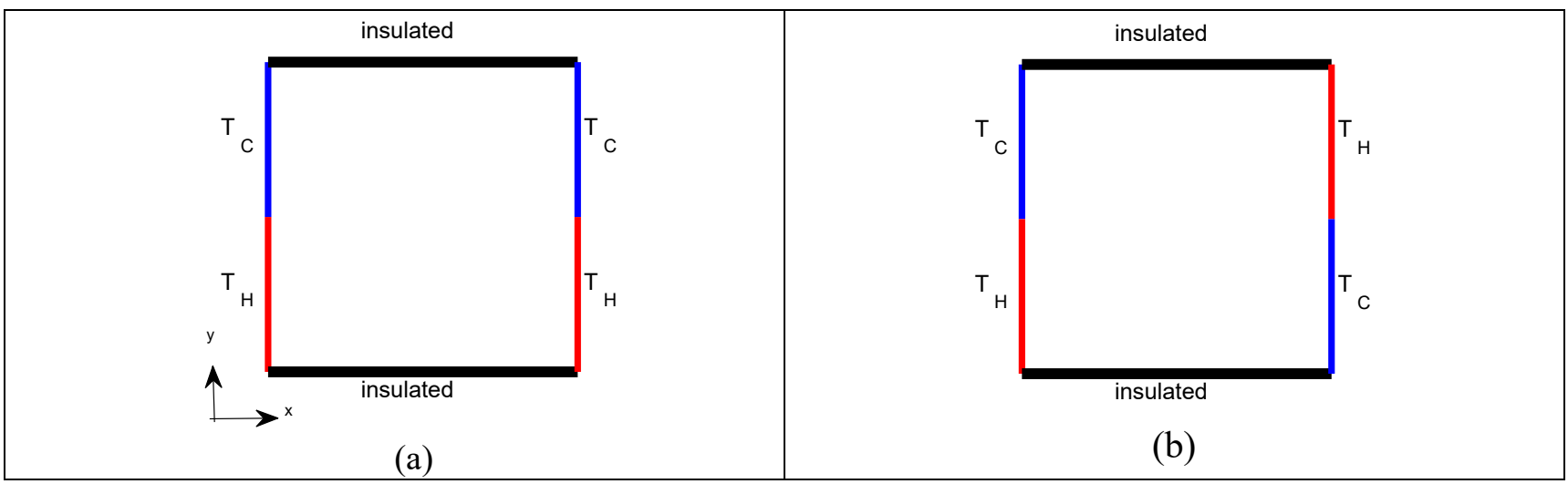

Fig. 1 Schematic of the cavity for two cases: (a) BC1 and (b) BC2.

In terms of the following dimensionless variables $x=x^{*} / L, \quad y=y^{*} / L ; \quad u=u^{*} L / \alpha, v=v^{*} L / \alpha ; t=t^{*} \alpha / L^{2}$; $p=p^{*} L^{2} /\left(\rho \alpha^{2}\right) ; \theta=\left(T-T_{c}\right) /\left(T_{h}-T_{c}\right)$ where $x^{*}, y^{*}$ are the coordinates; $u^{*}, v^{*}$ the velocities; $t^{*}$ the time; $p^{*}$ the pressure; $T$ the temperature; $L$ the width of the enclosure, the governing equations for mass, $\mathrm{x}-$ and $\mathrm{y}-$ momentum, and energy may be written for buoyancy-driven incompressible fluids as

$$
\begin{gathered}
\frac{\partial u}{\partial x}+\frac{\partial v}{\partial y}=0 \\
\frac{\partial u}{\partial t}+\frac{\partial u^{2}}{\partial x}+\frac{\partial u v}{\partial y}=-\frac{\partial p}{\partial x}+\operatorname{Pr} \nabla^{2} u \\
\frac{\partial v}{\partial t}+\frac{\partial u v}{\partial x}+\frac{\partial v^{2}}{\partial y}=-\frac{\partial p}{\partial y}+\operatorname{Pr} \nabla^{2} v+\operatorname{Ra} \operatorname{Pr} \theta \\
\frac{\partial \theta}{\partial t}+\frac{\partial u \theta}{\partial x}+\frac{\partial v \theta}{\partial y}=\nabla^{2} \theta
\end{gathered}
$$

where $\nabla^{2}$ is the two-dimensional Laplacian; $\operatorname{Pr}=v / \alpha$, the Prandtl number; $\operatorname{Ra}=\mathrm{g} \beta \Delta \mathrm{TL}^{3} / v \alpha$, the Rayleigh number which accounts for the coupling between energy and momentum balances, $g$ being the gravitational acceleration, $\beta$ the coefficient of thermal expansion of the fluid, $\Delta \mathrm{T}$ the temperature difference between hot and cold boundaries; $v$ the kinematic viscosity; and $\alpha$ the thermal diffusivity. Boussinesq approximation, which treats density as a constant in all equations except for the gravitational force term in the momentum equation, is used. Even though the computations are performed by using primitive variables, flow field 
results are presented in terms of the stream function $\Psi(\mathrm{u}=\partial \Psi / \partial \mathrm{y}, v=-\partial \Psi / \partial \mathrm{x})$. No slip boundary conditions are imposed on all walls. Unsteady governing equations are employed here since the evolution of flow pattern and the associated temporal behavior can only be captured by using time-dependent computations. The governing equations with primitive variables are solved on a staggered grid (99x99) by a two-dimensional numerical scheme developed by the lead author applying the Godunov scheme to convective terms and centered finite difference to diffusive terms. Formulations of the problem and details of the method have been described in an earlier work [Evren-Selamet et al. (1992)]. Next, the computational results are presented.

\section{RESULTS}

The accuracy of the numerical approach employed in the present study has already been validated through earlier comparisons [see Evren-Selamet et al. (1992)] with the benchmark numerical solution of de Vahl Davis (1983), therefore such details will be avoided here. In addition, for the present case of $\mathrm{BC}$, one specific comparison is made with Adnani et al.'s work: an excellent agreement is observed in Fig. 2 which compares the present horizontal velocity profile in the middle of the cavity for $\operatorname{Pr}=.71$ at $\operatorname{Ra}=10^{5}$. Since Adnani et al.'s numerical solutions are based on steady-state governing equations, periodic or unsteady flow predictions found here are, however, not comparable with their study. For example, they predicted four counter-rotating cells of same size for $\operatorname{Pr}=7$ at $\mathrm{Ra}=10^{5}$, while the present study observes those cells periodically changing in size and shape due to the ability of time-dependent governing equations to capture the temporal physics.

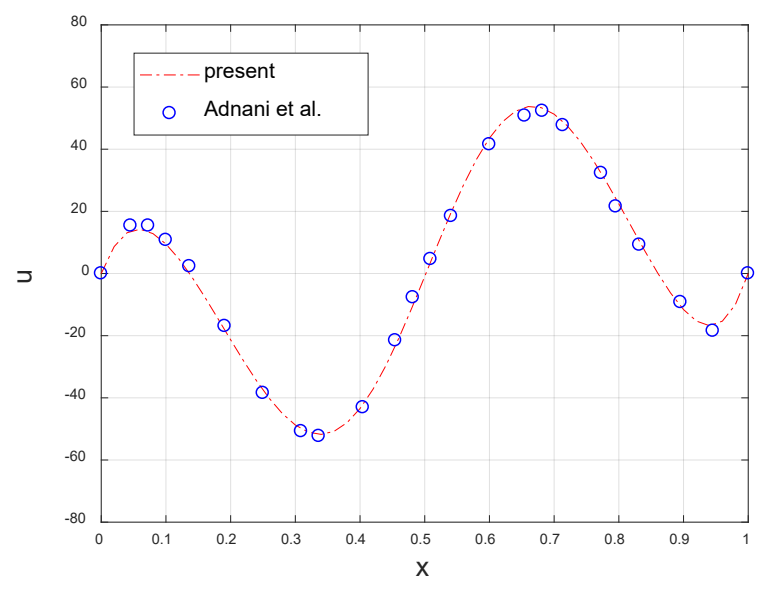

Fig. 2 Comparison of the horizontal velocity profile in the middle of the cavity for $\operatorname{Pr}=.71$ and $\mathrm{Ra}=10^{5}, \mathrm{BC}$.

Next, the results of the square cavity described earlier in Fig. 1 are presented in terms of streamlines and temperature profiles (isotherms), as well as the rate of heat transfer from the surfaces for $\operatorname{Pr}=.024$ (liquid metal), .71 (air), 6 (water), and 450 (silicon oil) at $\mathrm{Ra}=10^{4}-10^{6}$. Heat transfer rate is characterized by Nusselt $(\mathrm{Nu})$ number which is the dimensionless temperature gradient integrated over the walls.

\subsection{BC1}

Solutions are obtained with various $\mathrm{Pr}$ and $\mathrm{Ra}$ to examine their effect. For $\mathrm{Ra}=10^{4}$, (a) the streamlines and (b) isotherms are illustrated in Fig. 3 for $\mathrm{Pr}=.71$ and 450. Flow and temperature fields for $\mathrm{Pr}=.024$ and 6 are similar to those of $\operatorname{Pr}=.71$ at $\operatorname{Ra}=10^{4}$ : four counter-rotating cells appear for $\operatorname{Pr}=.024, .71$, and 6 , while two counterrotating cells for $\mathrm{Pr}=450$. When $\mathrm{Ra}$ is increased to $\mathrm{Ra}=10^{5}$ (Fig. 4), one main cell is now observed along with two corner cells in the flow field for $\operatorname{Pr}=.024$; one elongated cell with two larger corner cells for $\operatorname{Pr}=.71$; four-cell structure remains but with changing size and shapes for $\mathrm{Pr}=6$ and 450 (not included in the figure) since flow now exhibits a time-dependent sinusoidal behavior. Single main vortex persists for $\mathrm{Pr}=.024$ along with corner vortices of changing shape at all Ra considered here. Number of cells varies between 3 and 4 at $\mathrm{Ra} \geq 3 \times 10^{5}$ and 
$\operatorname{Ra} \geq 5 \times 10^{4}$ for $\operatorname{Pr}=.71$ and 6, respectively, while it remains 4 for $\operatorname{Pr}=450$. As a representative case of oscillating flows at $\mathrm{Ra}=10^{6}$, Fig. 5 demonstrates the transition from 3 cells to 4 and then back to 3 in one cycle of periodic variation for $\mathrm{Pr}=6$. Two convective cells first combine into one with time, which is then divided into two again with the pressure of growing two corner cells (top row). Bottom row shows corresponding isotherms which are confined to thin thermal boundary layer along the walls. Heat transfer is dictated primarily by those thermal boundary layers. Figure 6 depicts (a) the streamlines and (b) the isotherms for $\operatorname{Pr}=450$ at $\mathrm{Ra}=10^{6}$ at a specific time. The strengths of four cells all rotating opposite to each other change periodically. Isotherms again are concentrated along the walls. Next, the predictions associated with the second boundary condition (BC2) are discussed.

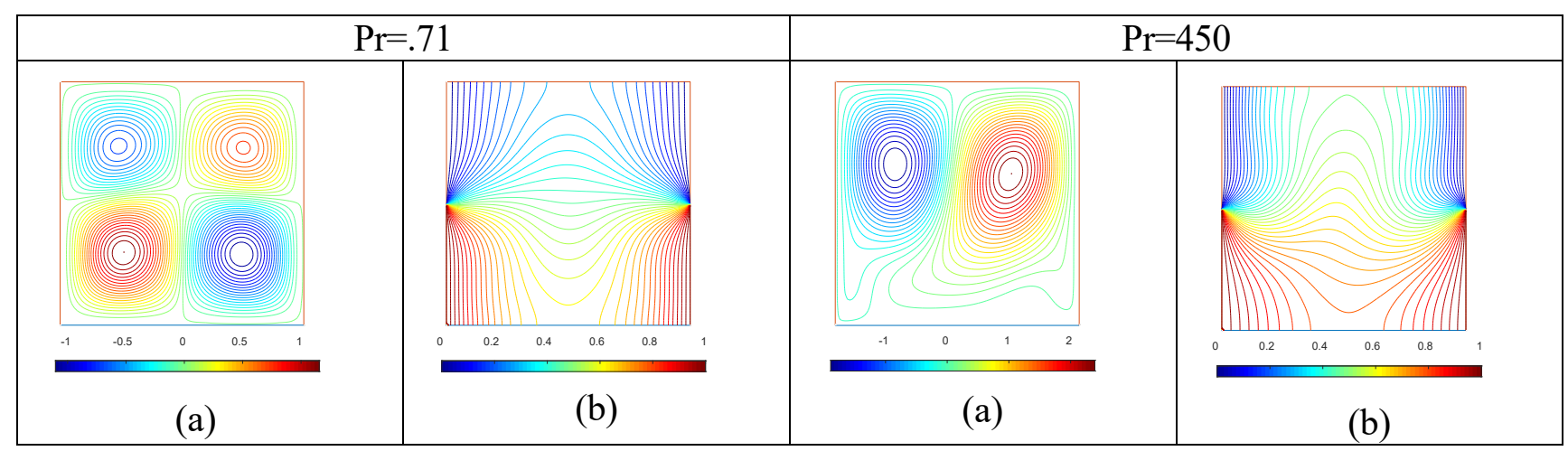

Fig. 3 (a) Streamlines and (b) isotherms for $\operatorname{Pr}=.71$ and $\operatorname{Pr}=450$ at $\mathrm{Ra}=10^{4} ; \mathrm{BC}$.

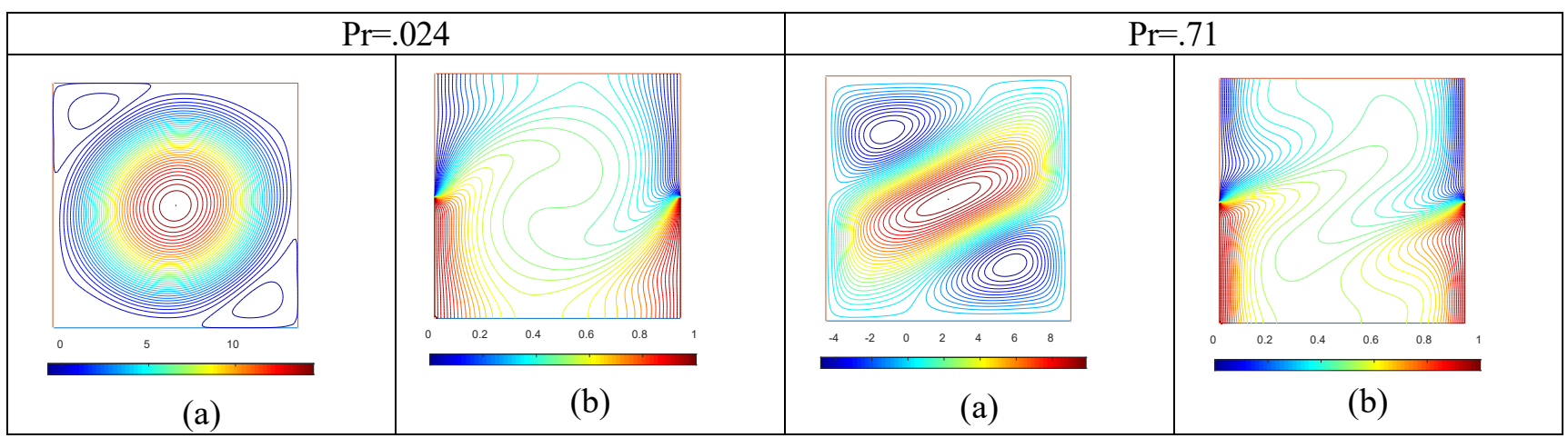

Fig. 4 (a) Streamlines and (b) isotherms for $\mathrm{Pr}=.024$ and $\mathrm{Pr}=.71$ at $\mathrm{Ra}=10^{5} ; \mathrm{BC} 1$.

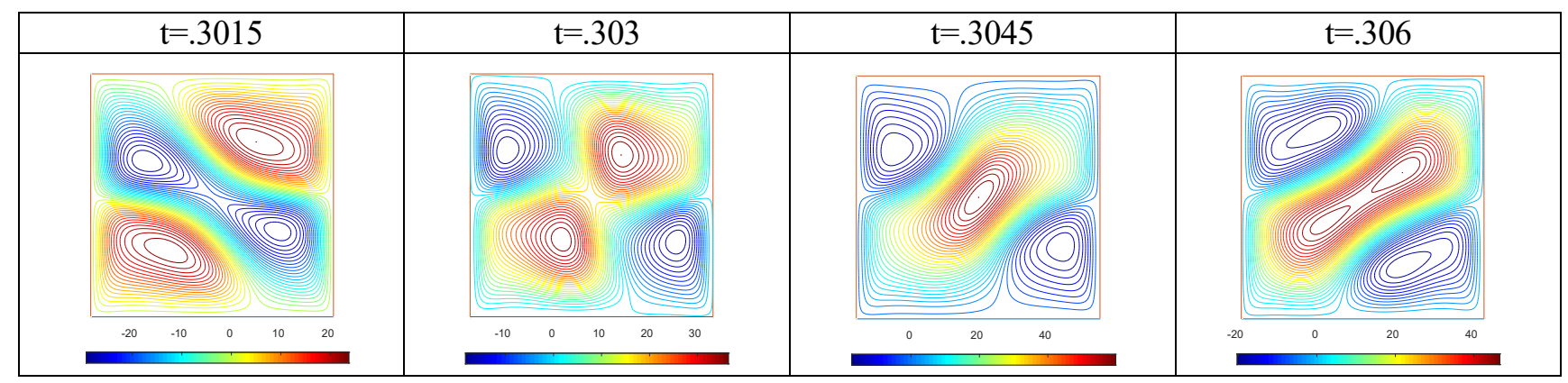




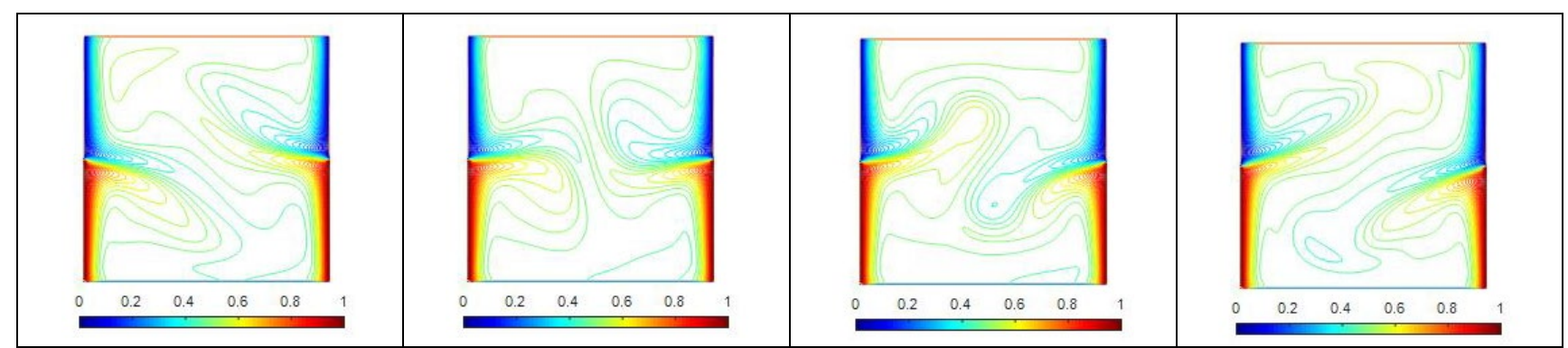

Fig. 5 Transient pattern of streamlines (top row) and isotherms (bottom row) in one cycle of oscillation for $\operatorname{Pr}=6$ and $\mathrm{Ra}=10^{6}$.

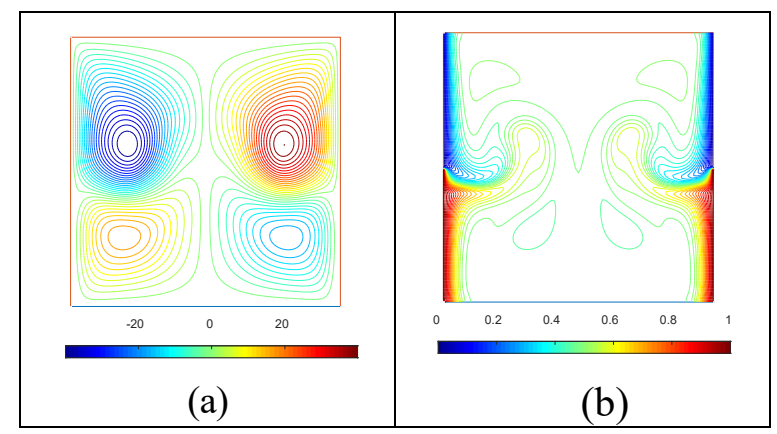

Fig. 6 (a) Streamlines and (b) isotherms at $\mathrm{t}=.25$ for $\operatorname{Pr}=450$ and $\mathrm{Ra}=10^{6}$.

\subsection{BC2}

For this case, the bottom half of right wall is at a colder temperature than the top half (recall Fig. 1b). Unlike $\mathrm{BC} 1, \mathrm{BC} 2$ produces a pair of counter-rotating cells on top of each other for all Pr considered here. To save space, Fig. 7 represents (a) the streamlines and (b) the isotherms, only for $\mathrm{Pr}=.024$ and .71 at $\mathrm{Ra}=10^{5}$. The centers of circulating patterns are shifted to the right or left wall depending on Pr but both cells are symmetric about the mid-height. Isotherms are observed to be intense close to the walls. Higher Ra results in a similar structure but with two additional small cells inside the outer large cell. More stable solutions are obtained with this altered boundary condition for $\mathrm{Pr}=.71,6$, and 450 . The evolution of $\mathrm{Nu}$ which represents the sum of the averaged heat transfer rate along the heated/cooled halves of both vertical side walls gives a clear picture of how modifying the boundary conditions from type 1 to 2 affects the heat transfer rate at various Pr and Ra.

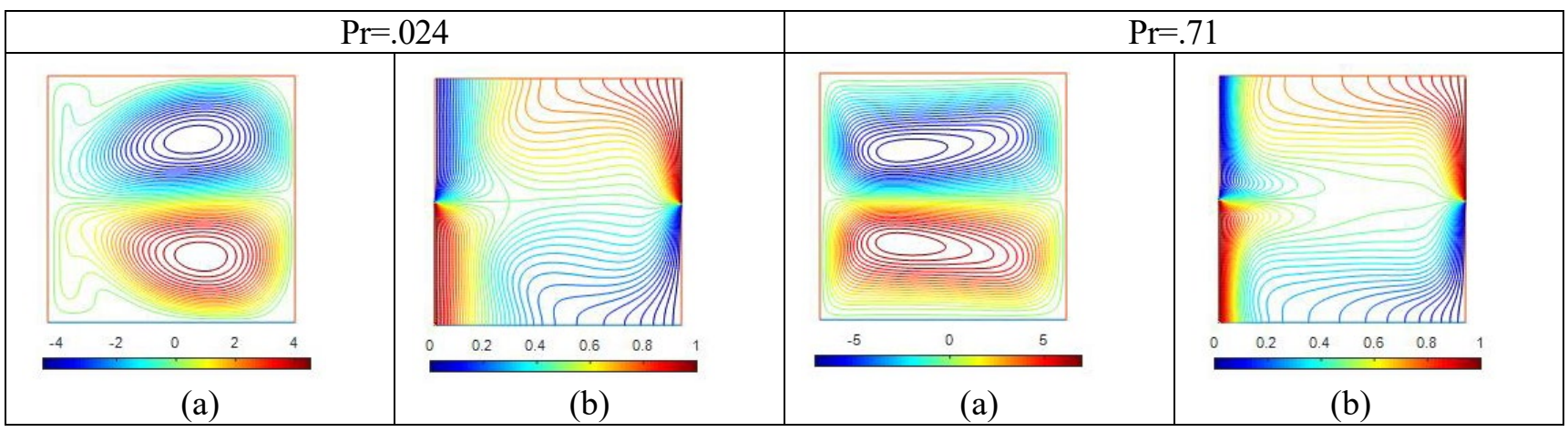

Fig. 7 Streamlines (a) and isotherms (b) for $\operatorname{Pr}=.024$ and $\operatorname{Pr}=.71$ at $\mathrm{Ra}=10^{5} ; \mathrm{BC} 2$. 
Figure 8 compares the evolution of $\mathrm{Nu}_{\mathrm{H}}$ with $\mathrm{BC} 1$ (maroon) and $\mathrm{BC} 2$ (green) for $\mathrm{Pr}=.024, .71,6$, and 450 at $\mathrm{Ra}=10^{5}, 3 \times 10^{5}, 5 \times 10^{5}$, and $10^{6}$. For $\mathrm{Pr}=.024, \mathrm{Nu}$ for $\mathrm{BC} 2$ at $\mathrm{Ra}=10^{5}$ shows early oscillatory behavior, and then reaches nearly a steady final value - same as $\mathrm{BC} 1$ which does not exhibit oscillations along the way. At higher $\mathrm{Ra}$, both $\mathrm{BC} 1$ and $\mathrm{BC} 2$ show periodic oscillations: $\mathrm{BC} 2$ converges to an oscillatory behavior with its amplitude and mean $\mathrm{Nu}_{\mathrm{H}}$ being higher than those of $\mathrm{BC} 1$. For $\mathrm{Pr}=.71, \mathrm{Nu}_{\mathrm{H}}$ at $\mathrm{Ra}=10^{5}$ reaches a steady state smoothly for both types of boundary conditions; $\mathrm{BC} 1$ shows early symptoms of oscillations at $\mathrm{Ra}=3 \times 10^{5}$ with such oscillations growing at $\mathrm{Ra}=5 \times 10^{5}$ and becoming chaotic at $\mathrm{Ra}=10^{6}$, whereas $\mathrm{BC} 2$ approaches a steady solution for all Ra considered. For $\mathrm{Pr}=.71$, switching boundary condition from 1 to 2 not only increases the heat transfer rate but also stabilizes the flow field. Similarly, at $\mathrm{Pr}=6, \mathrm{Nu}_{\mathrm{H}}$ for $\mathrm{BC} 2$ remains higher than that of $\mathrm{BC} 1$. For $\mathrm{BC} 1$, $\mathrm{Nu}_{\mathrm{H}}$ is periodic at $\mathrm{Ra}=10^{5}$ and $3 \times 10^{5}$, becoming nearly steady at higher $\mathrm{Ra}$, whereas, for $\mathrm{BC} 2$, it is steady for all the discrete $\mathrm{Ra}$ considered here similar to $\mathrm{Pr}=.71$. When $\mathrm{Pr}$ is increased further to $450, \mathrm{Nu}_{\mathrm{H}}$ shows regular sinusoidal variation at all $\mathrm{Ra}$ for $\mathrm{BC} 1 . \mathrm{BC} 2$ again stabilizes the flow but the mean heat transfer rate is lowered slightly relative to $\mathrm{BC} 1$ at $\mathrm{Ra}=5 \times 10^{5}$ (and $7.5 \times 10^{5}$ [not included in the figure]). The effects of two types of boundary conditions on the temporal variation of $\mathrm{Nu}_{\mathrm{H}}$ are depicted in Fig. 9 at four different $\mathrm{Pr}$ and various $\mathrm{Ra}$.

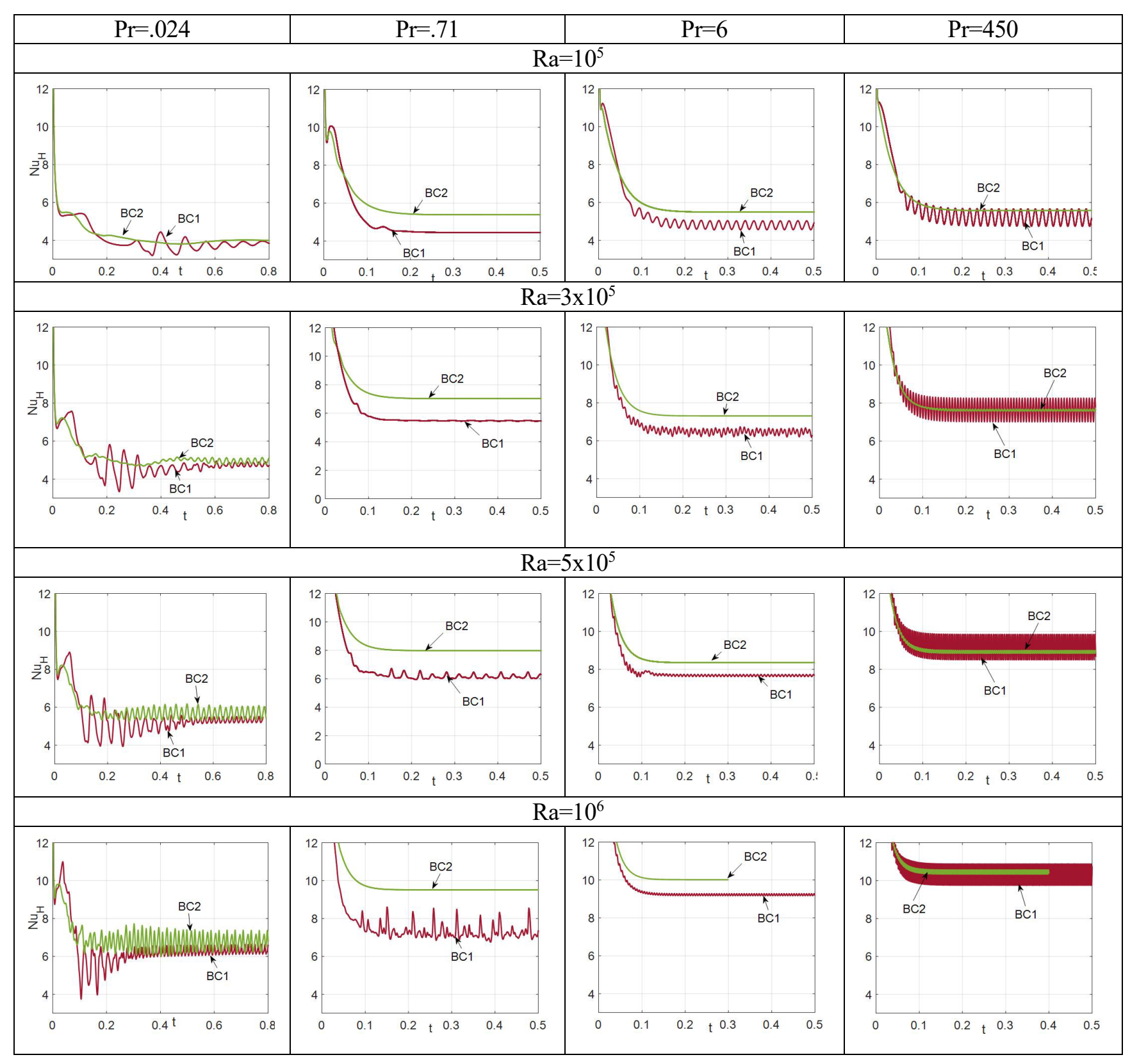


Fig. 8 Temporal variation of $\mathrm{Nu}_{\mathrm{H}}$ with two different boundary conditions for $\mathrm{Pr}=.024, .71,6$, and 450 at various Ra.

Examining the left column $(\mathrm{BC} 1)$ and the right column $(\mathrm{BC} 2)$ of Fig. 9 reveals that $\mathrm{BC} 2$ stabilizes the heat transfer and flow field for $\mathrm{Pr}=.71,6$, and 450 for all the cases considered here. This stabilizing effect did not occur for $\mathrm{Pr}=.024$. Lowest $\mathrm{Nu}$ number is predicted with the smallest Pr number as it is expected due to much higher conductivity of the fluid.

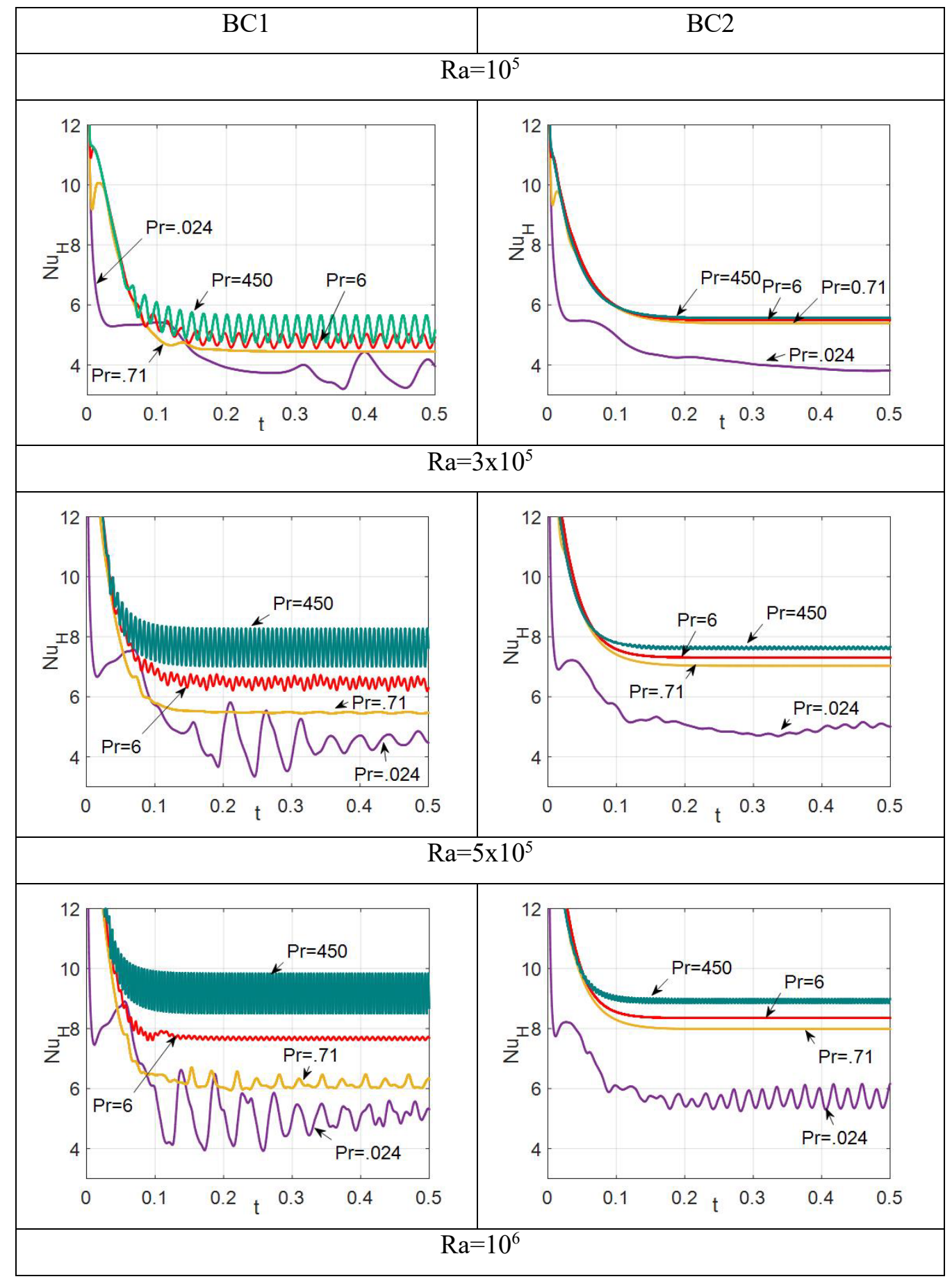




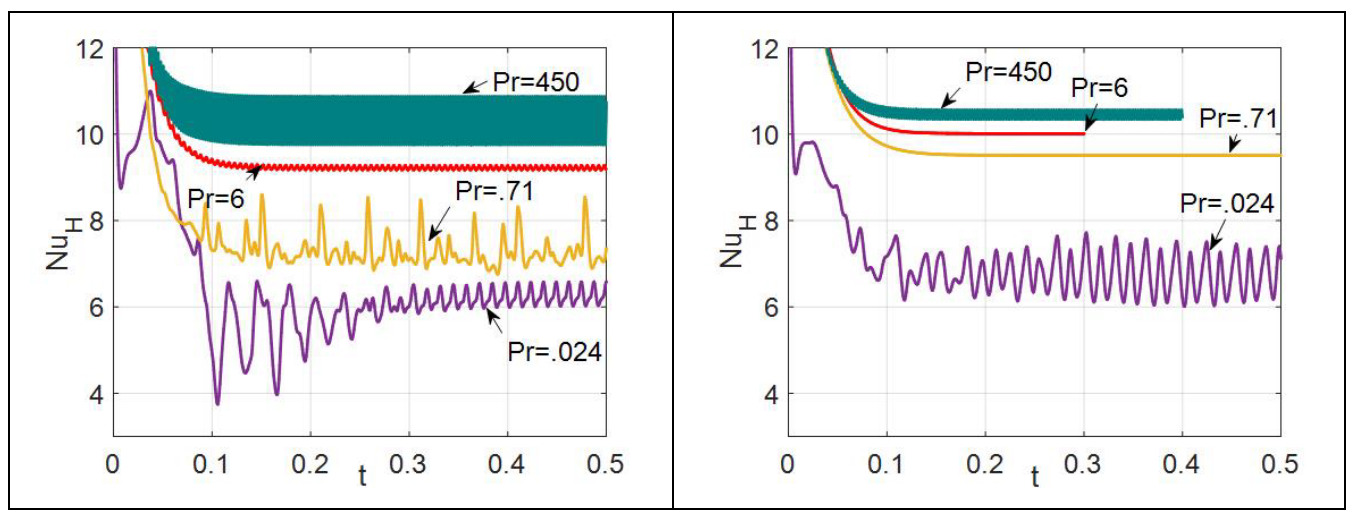

Fig. 9 Comparison of temporal variation of $\mathrm{Nu}_{\mathrm{H}}$ with two different boundary conditions for $\mathrm{Pr}=.024, .71,6$ and 450 at various Ra.

Finally, mean value of $\mathrm{Nu}_{\mathrm{H}}$ vs. Ra is shown in Fig. 10 for $\mathrm{BC} 1$ (solid line) and $\mathrm{BC} 2$ (dashed line) at four Pr used in this study. Most significant increase in $\mathrm{Nu}$ from $\mathrm{BC} 1$ to $\mathrm{BC} 2$ is obtained for $\mathrm{Pr}=.71$ (blue) followed by $\mathrm{Pr}=6$ (red) and $\mathrm{Pr}=.024$ (magenta); $\mathrm{Nu}_{\mathrm{H}}$ appears to decrease slightly (again from $\mathrm{BC} 1$ to $\mathrm{BC} 2$ ) for $\mathrm{Pr}=450$ (green) around $\mathrm{Ra}=5 \times 10^{5}$ and $7.5 \times 10^{5}$, in contrast to the behavior at smaller Pr. High viscosity of the silicon oil may be accountable for this behaviour. It is therefore concluded, from heat transfer enhancement viewpoint, that $\mathrm{BC} 2$ is most effective for $\mathrm{Pr}=.71$ and 6 , while also stabilizing the flow and temperature field. For these fluids $\mathrm{BC} 2$ alters the flow pattern from multi-cell to two-cell structure and energy transport by two cells appears better than that of multi cells leading enhancement of the average heat transfer rate inside the enclosure. This is also observed by Sivasankaran and Pan (2014).

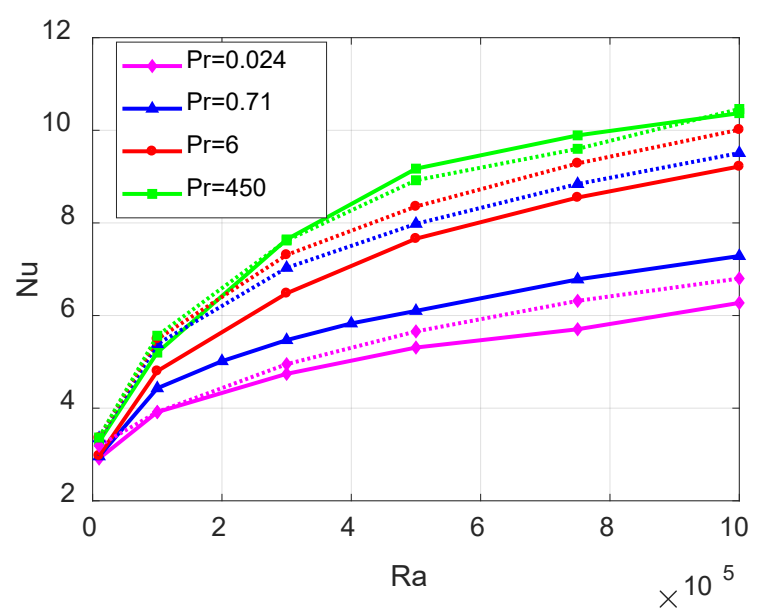

Fig. 10 Comparison of mean value of $\mathrm{Nu}_{\mathrm{H}}$ for $\mathrm{Pr}=.024, .71,6$, and $450 \mathrm{vs.}$ Ra for $\mathrm{BC} 1$ (solid line) and 2 (dashed line).

\section{CONCLUSIONS}

Natural convection driven by temperature differences between partially heated and cooled vertical walls in a square cavity is studied numerically. The effect of $\mathrm{Pr}$ and $\mathrm{Ra}$ on the flow regime and heat transfer is established along with two different thermal boundary conditions. $\mathrm{BC} 2$ is observed to stabilize the temperature and flow field for $\operatorname{Pr}=.71,6$, and 450 at all cases considered here. The trends with $\operatorname{Pr}=.024$ are, however, not unidirectional: low Ra range manifests the similar stabilizing effect, yet, higher $\mathrm{Ra}$ range $\left(\mathrm{Ra}=5 \times 10^{5}\right.$ and $\left.10^{6}\right)$ maintains the oscillations, while also exhibiting a level of growth in amplitudes with time. $\mathrm{BC} 2$ is found to increase the heat transfer rate noticeably for $\mathrm{Pr}=.024, .71$, and 6 , with the most impact observed for $\operatorname{Pr}=.71$. 


\section{REFERENCES}

[1] S. Ostrach, "An Analysis of Laminar Free-Convection Flow and Heat Transfer About a Flat Plate," NACA, TN 2635, 1952.

[2] K. Kubleck, G. P. Merker and J. Straub, "Advanced Numerical Computation of TwoDimensional Time-Dependent Free Convection in Cavities," International Journal of Heat and Mass Transfer, vol. 23, pp. 203-217, 1980.

[3] D. Poulikakos, "Natural Convection in a Confined Fluid-Filled Space Driven by a Single Vertical Wall with Warm and Cold Regions," Journal of Heat Transfer, vol. 107, pp. 867-876, 1985.

[4] E. Bilgen and R. B. Yeddler, "Natural Convection in Enclosure with Heating and Cooling by Sinusoidal Temperature Profiles one One Side," Inernational Journal of Heat and Mass Transfer, vol. 50, pp. 139-150, 2007.

[5] Q. Deng and J. Chang, "Natural Convection in a Rectangular Enclosure with Sinusoidal Temperature Distributions on Both Side Walls," Numerical Heat Transfer, Part A, vol. 54, pp. 507-524, 2008.

[6] S. Sivasankaran and K. L. Pan, "Natural Convection of Nanofluids in a Cavity with Nonuniform Temperature Distributions on Side Walls," Numerical Heat Transfer, Part A, vol. 65, pp. 247-268, 2014.

[7] M. Adnani, B. Meziani, O. Ourrad and M. Zitoune, "Natural Convection in a Square Cavity: Numerical Study for Different Values of Prandtl Numbers," Fluid Dynamics and Materials Processing, vol. 12, no. 1, pp. 1-14, 2016.

[8] E. Evren-Selamet and A. Selamet, "Natural Convection for Air and Molten Gallium in Squareand Elbow-shaped Enclosures," Applied Mechanics and Materials, vol. 789, pp. 462-470, 2015.

[9] E. Evren-Selamet, A. Selamet and R. Dehner, "Effect of Fin Orientation and Length on the Rayleigh-Benard Convection," Journal of Energy and Power Engineering, vol. 11, pp. 317335, 2017.

[10] E. Evren-Selamet, A. Selamet and R. Dehner, "Simulation of the Rayleigh-Benard Convection in a Finned Cavity Filled with Liquid Gallium," 3rd Thermal and Fluids Enginering Conference (TFEC), pp. 551-560, 2018.

[11] E. Evren-Selamet V. S. Arpaci and C. Borgnakke, "Simulation of Laminar Buoyancy-driven Flows in an Enclosure," Numerical Heat Transfer Part A, vol. 22, pp. 401-420, 1992.

[12] G. V. Davis, "Natural Convection of Air in a Square Cavity: A Bench Mark Numerical Soluton," Inernational Journal of Numerical Methods in Fluids, vol. 3, no. 3, pp. 249-264, 1983. 